\title{
Hydrothermal Synthesis of Lanthanide Stannates Pyrochlore Nanocrystals for Catalytic Combustion of Soot Particulates
}

\author{
Xiaomin Zhang, Xuhui Liu, Peng Lu, Liguo Wang, Zhaoliang Zhang, \\ Xiuju Wang, and Zhongpeng Wang \\ School of Resources and Environment, University of Jinan, 336 Nanxinzhuangxi Road, Jinan 250022, China \\ Correspondence should be addressed to Zhongpeng Wang; chm_wangzp@ujn.edu.cn
}

Received 2 November 2014; Revised 16 February 2015; Accepted 3 March 2015

Academic Editor: Siang-Piao Chai

Copyright (c) 2015 Xiaomin Zhang et al. This is an open access article distributed under the Creative Commons Attribution License, which permits unrestricted use, distribution, and reproduction in any medium, provided the original work is properly cited.

\begin{abstract}
Nanocrystalline $\mathrm{La}_{2} \mathrm{Sn}_{2} \mathrm{O}_{7}$ and $\mathrm{La}_{2} \mathrm{Sn}_{1.8} \mathrm{Co}_{0.2} \mathrm{O}_{7}$ with a phase-pure pyrochlore structure were synthesized by a hydrothermal method, and their catalytic activity was investigated for soot combustion. The as-synthesized catalysts presented relatively larger surface area, and pore volume, which was benefit to the gas molecule diffusion in the reaction. A uniform spherical structure with particle size of 200-500 nm was found in SEM. The samples via hydrothermal route are more active for catalytic soot combustion, ascribing to the spherical morphology, high surface area and improved oxygen mobility. After Co, the reducibility was improved and surface oxygen vacancy was produced, resulting in the enhanced activity and selectivity to $\mathrm{CO}_{2}$ formation.
\end{abstract}

\section{Introduction}

Soot particulates from diesel engine have caused serious problems to global environment and human health [1]. The automobile exhausts have been recognized as one of the important sources for the frequent haze weather in China now. Filtration and controllable regeneration within the exhaust stream are among the most promising methods for soot removal, while the key technology is oxidation catalysis $[2,3]$. In a previous work, the kinetics of the soot $-\mathrm{O}_{2}$ reaction can be explained by the following reaction mechanism [4]:

$$
\begin{aligned}
\mathrm{O}_{2} & \longrightarrow 2 \mathrm{O}_{\mathrm{ad}} \\
\mathrm{C}_{\mathrm{f}}+\mathrm{O}_{\mathrm{ad}} & \longrightarrow \mathrm{C}^{*}[\mathrm{O}] \\
\mathrm{C}^{*}[\mathrm{O}]+\mathrm{O}_{\mathrm{ad}} & \longrightarrow \mathrm{CO}_{2}(\mathrm{~g})\left(+n \mathrm{C}_{\mathrm{f}}\right) \\
\mathrm{C}^{*}[\mathrm{O}]+\frac{1}{2} \mathrm{O}_{2}(\mathrm{~g}) & \longrightarrow \mathrm{CO}_{2}(\mathrm{~g})\left(+n \mathrm{C}_{\mathrm{f}}\right)
\end{aligned}
$$

Gaseous $\mathrm{O}_{2}$ is adsorbed dissociatively on the catalyst surface (equation (1)), and the resulting atomic $\mathrm{O}_{\mathrm{ad}}$ species then attack the reactive free carbon site, $\mathrm{C}_{\mathrm{f}}$, to give an oxygencontaining active intermediate, $\mathrm{C}^{*}[\mathrm{O}]$ (equation (2)). The reaction between the $\mathrm{C}^{*}[\mathrm{O}]$ intermediate and either $\mathrm{O}_{a d}$ or gaseous $\mathrm{O}_{2}$ produces $\mathrm{CO}_{2}$ through reaction (3) or (4), reproducing the reactive $\mathrm{C}_{\mathrm{f}}$ sites on soot surface.

In the past decades, many materials have been applied in oxidation catalysis, with transition-metal oxides [5-7], alkaline metal oxides [8-11], perovskite-like type oxides [12, $13]$, noble metals [3, 14], and ceria-based oxides $[15,16]$ being the outnumbering materials. However, these catalysts had some limitations in commercialization, such as the high cost of noble metals catalysts, poor stability of alkaline metal oxides, and weak activity in low temperature for transitionmetal oxides. Thus, a cheap and efficient substitute with lowtemperature activity and high selectivity is still desired.

During the past decade, pyrochlore-type oxides have emerged as important functional materials due to their interesting thermal, electrical, optical, magnetic, and catalytic properties [17]. Pyrochlores have the empirical formula $\mathrm{A}_{2} \mathrm{~B}_{2} \mathrm{O}_{7}$, where $\mathrm{A}$ is a rare earth trivalent element and $\mathrm{B}$ is a tetravalent transition element. Their structure formula is often written as $\mathrm{B}_{2} \mathrm{O}_{6} \cdot \mathrm{A}_{2} \mathrm{O}^{\prime}$, which emphasizes that the arrangement consists of a three-dimensional network of octahedron $\left(\mathrm{B}_{2} \mathrm{O}_{6}\right)$ linked with an $\mathrm{A}_{2} \mathrm{O}^{\prime}$ tetrahedron in the interstices. For possibility of the existence of any pyrochlore compound, there are two criteria: (1) the ratio of the ionic radius of the cation at the $\mathrm{A}$ site to that at the $\mathrm{B}$ site 
must be between 1.46 and 1.80; (2) the chemical valences of various ions must make the compound to be charge neutrality [18]. The cations at the $\mathrm{A}$ site and the $\mathrm{B}$ site in the lattice can be replaced by the cations with different chemical valence or different oxidation reduction property to synthesize the various kinds of pyrochlore compounds with different physical or chemical properties, if the criteria can be satisfied. Substitutions of metals at the A or B sites in certain pyrochlore formulations can yield oxygen vacancies. As is known, the A site metal can be often replaced by alkali metal or other lanthanide elements whilst B site cation can be substituted by transition metals, such as Fe, Mn, Co, and $\mathrm{Cu}$. By selecting $\mathrm{A}$ and $\mathrm{B}$ cations and/or introducing lattice defects, oxide pyrochlores exhibit improved redox property and catalytic activity. Among various pyrochlore oxides, lanthanide stannates, $\mathrm{Ln}_{2} \mathrm{Sn}_{2} \mathrm{O}_{7}(\mathrm{Ln}=\mathrm{Y}$, La-Lu), have been well investigated in various environment-related high temperature catalytic reactions such as NO reduction [19], NO decomposition [20], CO oxidation [21], and catalytic combustion of methane [22, 23]. In our previous works [24], transition metal doped lanthanum stannate oxides with pyrochlore structure prepared by coprecipitation exhibited moderate catalytic activity for soot combustion in the presence of $\mathrm{NO}+\mathrm{O}_{2}$.

With regard to the particle size and morphology, nanostructured materials are usually better for heterogeneous catalytic reactions due to their high surface area and quantum effects. Therefore, much emphasis has been laid on the shape control and the size control recently $[15,25,26]$. The surface particle sizes of nanometer material are small. Surface atoms on nanometer catalysts have extra and high surface energies and they are good at mobility; therefore, the contact between catalysts and soot can be improved even under loose contact conditions [27]. The development of adequate synthetic methods for the preparation of nanometric powders at low temperatures and atmospheric pressure is a task of great interest. Although various methods, such as conventional solid state approach [28], sol-gel processing, coprecipitation route [24], and combustion method [29], have been used to prepare $\mathrm{La}_{2} \mathrm{Sn}_{2} \mathrm{O}_{7}$, only hydrothermal route [30] has been proved to be a facial approach to fabricate $\mathrm{La}_{2} \mathrm{Sn}_{2} \mathrm{O}_{7}$ nanocrystallites with uniform particle sizes, high surface areas, regular shapes, and pure phases. It requires milder reaction conditions, compared with the high-temperature method.

Motivated by the above considerations, phase-pure lanthanum stannate pyrochlore oxides have been prepared via a simple hydrothermal technique. The catalysts showed nanosphere morphology, large surface area, and improved redox properties, which resulted in high catalytic activity and selectivity for soot combustion in the presence of oxygen.

\section{Experimental}

2.1. Catalyst Preparation. All the reagents were analytically pure, commercially available, and used without further purification. $\mathrm{La}_{2} \mathrm{Sn}_{2} \mathrm{O}_{7}$ and $\mathrm{La}_{2} \mathrm{Sn}_{1.8} \mathrm{Co}_{0.2} \mathrm{O}_{7}$ pyrochlore oxides were prepared with both hydrothermal method and coprecipitation method. The suitable amounts of $\mathrm{La}\left(\mathrm{NO}_{3}\right)_{3} \cdot 6 \mathrm{H}_{2} \mathrm{O}, \quad \mathrm{SnCl}_{4} \cdot 5 \mathrm{H}_{2} \mathrm{O}, \quad \mathrm{Co}\left(\mathrm{NO}_{3}\right)_{2} \cdot 6 \mathrm{H}_{2} \mathrm{O}$ were dissolved in deionized water. The mixed salt solution $(100 \mathrm{~mL})$ and a basic solution $(1 \mathrm{M} \mathrm{NaOH})$ were simultaneously added dropwise into $100 \mathrm{~mL}$ of deionized water at constant $\mathrm{pH}(9.5 \pm 0.5)$ under vigorous magnetic stirring. Precipitates were aged in suspension for $1 \mathrm{~h}$ under stirring in static air and then divided into two parts for different preparation methods. One part was transferred into a Teflon-lined stainless autoclave $(200 \mathrm{~mL}$ capacity) that was filled with the mixture to $80 \%$ of the total volume. The autoclave was kept at a temperature $180^{\circ} \mathrm{C}$ for $18 \mathrm{~h}$ and then cooled to ambient temperature naturally. The resulting precipitates were washed with deionized water and ethanol thoroughly and dried at $80^{\circ} \mathrm{C}$ in an oven for $6 \mathrm{~h}$ before further characterization. The two pyrochlore oxides prepared by the hydrothermal method were denoted as LSO and CoLS. For comparison, the other part of precipitates was used for high temperature calcinations to prepare pyrochlore oxides. The precipitates was filtered and thoroughly washed with deionized water, then dried at $80^{\circ} \mathrm{C}$ for $12 \mathrm{~h}$, and further dried at $120^{\circ} \mathrm{C}$ overnight. Finally, the two reference catalysts were obtained by calcination at $900^{\circ} \mathrm{C}$ for $5 \mathrm{~h}$ in air, denoted as LSO-c and CoLS-c, respectively.

2.2. Catalyst Characterization. XRD was carried out with a BRUKER-AXS D8 Advance X-ray diffractometer over a $2 \theta$ range from 10 to $80^{\circ}$ at a scan rate of $3^{\circ} / \mathrm{min}$. $\mathrm{N}_{2}$ adsorptiondesorption isotherms were performed using a Micromeritics ASAP 2020 surface area analyzer after outgassing at $200^{\circ} \mathrm{C}$ for $5 \mathrm{~h}$ prior to analysis. The specific surface areas were calculated with the BET equation on the basis of the adsorption data. The morphology of the samples was examined with scanning electron microscopy (SEM, QUANTA FEG250). The particle size distribution histogram was measured with dynamic light scattering (DLS) using a Zetasizer Nano ZS instrument. Temperature-programmed reduction with $\mathrm{H}_{2}$ $\left(\mathrm{H}_{2}\right.$-TPR) experiments was performed in a quartz reactor with a thermal conductivity detector (TCD) to monitor the $\mathrm{H}_{2}$ consumed. A $50 \mathrm{mg}$ sample was pretreated in situ at $500^{\circ} \mathrm{C}$ for $0.5 \mathrm{~h}$ in a flow of $\mathrm{O}_{2}$ and cooled to room temperature in the presence of $\mathrm{O}_{2}$. TPR was conducted at $10^{\circ} \mathrm{C} / \mathrm{min}$ up to $900^{\circ} \mathrm{C}$ in a $50 \mathrm{~mL} / \mathrm{min}$ flow of $5 \mathrm{vol} . \% \mathrm{H}_{2}$ in $\mathrm{N}_{2}$. The FTIR spectra were recorded on a Thermo Nicolet 6700 spectrometer over $400-4000 \mathrm{~cm}^{-1}$ after $32 \mathrm{scans}$ at a resolution of $4 \mathrm{~cm}^{-1}$.

2.3. Catalytic Reactions. The model soot used in this study was Printex-U from Degussa with surface area of $93.5 \mathrm{~m}^{2} / \mathrm{g}$. The mean agglomerate size measured using a laser particle size analyzer was about $177 \mathrm{~nm}[10]$.

The catalytic reactions for soot combustion were performed by a TPO technique in a fixed-bed flow reactor as described in our previous works [31, 32]. The soot was mixed with the catalyst in a weight ratio of $1: 9$ in an agate mortar for $10 \mathrm{~min}$, which results in a tight contact. A $50 \mathrm{mg}$ sample of the soot/catalyst mixture was pretreated in $\mathrm{He}$ $(100 \mathrm{~mL} / \mathrm{min})$ at $200^{\circ} \mathrm{C}$ for $1 \mathrm{~h}$ to remove surface-adsorbed species. After cooling down to ambient temperature naturally 
TABLE 1: Structural information of the pyrochlore catalysts.

\begin{tabular}{|c|c|c|c|c|c|}
\hline Samples & $S_{\mathrm{BET}}\left(\mathrm{m}^{2} / \mathrm{g}\right)$ & $V_{P}\left(\mathrm{~cm}^{3} / \mathrm{g}\right)$ & $D_{P}(\mathrm{~nm})$ & $v(\mathrm{Sn}-\mathrm{O})\left(\mathrm{cm}^{-1}\right)$ & $X_{s}(\mathrm{~nm})$ \\
\hline LSO & 39.0 & 0.057 & 5.9 & 605 & 20.3 \\
\hline LSO-c & 7.6 & 0.012 & 6.7 & 598 & 40.7 \\
\hline CoLS & 27.0 & 0.041 & 6.0 & 607 & 19.3 \\
\hline CoLS-c & 12.7 & 0.023 & 7.3 & 603 & 32.4 \\
\hline
\end{tabular}

$S_{\mathrm{BET}}$ : the BET specific surface areas; $V_{P}$ : total pore volume; $D_{P}$ : average pore diameter; $X_{s}$ : crystallite size.

and replacing the helium flow with the reaction gas flow $\left(5 \% \mathrm{O}_{2} / \mathrm{He}\right.$, flow rate $100 \mathrm{~mL} / \mathrm{min}$ ), the TPO was started at a heating rate of $4^{\circ} \mathrm{C} / \mathrm{min}$. The outlet gas was analyzed online by a gas chromatograph (GC) (SP-6890, Shandong Lunan Ruihong Chemical Instrument Corporation, China) with a flame ionization detector after separating them over a TDX01 column and converting to methane over a $\mathrm{Ni}$ catalyst at $360^{\circ} \mathrm{C}$. The sampling interval by the GC is 4 minutes. The characteristic temperatures from the TPO profiles, $T_{5}, T_{50}$, and $T_{90}$, were defined as the temperatures at which $5 \%, 50 \%$, and $90 \%$ of the soot is converted, respectively. The selectivity to $\mathrm{CO}_{2}$ formation $\left(\mathrm{S}_{\mathrm{CO}_{2}}\right)$ was defined as the percentage outlet $\mathrm{CO}_{2}$ concentration divided by the sum concentrations of the outlets $\mathrm{CO}_{2}$ and $\mathrm{CO}$.

\section{Results and Discussion}

3.1. XRD Analysis. The XRD patterns of the pyrochlore catalysts are shown in Figure 1. It can be seen that the four samples show typical diffraction patterns of $\mathrm{La}_{2} \mathrm{Sn}_{2} \mathrm{O}_{7}$ (JCPDS 13-0082) with pyrochlore structure conforming to the Fd-3m space group. Thus, single-phase lanthanum stannate pyrochlore oxides can be prepared by both hydrothermal and coprecipitation method. As expected, the samples via hydrothermal technique (LSO and CoLS) exhibit broad and weak diffraction peaks in comparison with those by coprecipitation method (LSO-c and CoLS-c). The crystallite size $\left(X_{s}\right)$ of the solids, listed in Table 1, was calculated from the (222) diffraction peak around $2 \theta$ value of $29^{\circ}$ by using Debye-Scherrer equation. According to the equation, the crystallite size is in inverse proportion to the FWHM values of the peak [33]. The hydrothermal catalysts have a pyrochlore crystalline size of 19-20 nm, while the coprecipitation method produces samples with larger size of $30-40 \mathrm{~nm}$. In addition, the characteristic diffractions of CoLS indicate that the Co cations are well distributed in the pyrochlore structure and a small quantity of Co in the pyrochlores does not change the crystal purity since there is no peak related with other compounds. Meanwhile, oxygen vacancies can be yielded with replacement of $\mathrm{Sn}^{4+}$ by a lower valence transition metal ion to maintain electrostatic charge neutrality. In this sense, the oxides should be expressed by $\mathrm{La}_{2} \mathrm{Sn}_{1.8} \mathrm{Co}_{0.2} \mathrm{O}_{7-\delta}$ ( $\delta=$ oxygen vacancy). The formed oxygen vacancies may influence the oxygen mobility in the oxidation reactions.

3.2. SEM Morphology. The SEM morphology of the samples is shown in Figure 2. SEM observation revealed that the hydrothermal catalysts (Figures 2(a) and 2(b)) show nearly

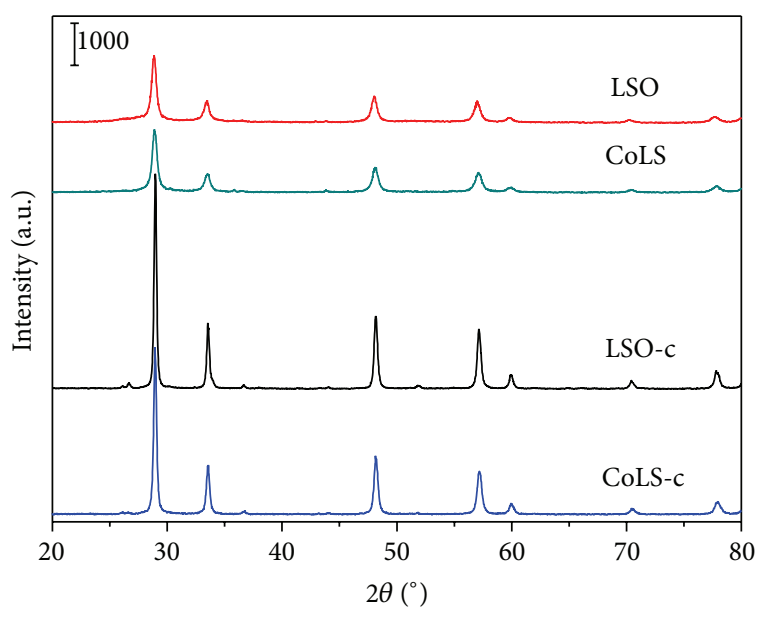

FIGURE 1: XRD patterns of pyrochlore oxide prepared by hydrothermal method and coprecipitation method.

spherical particle with rough surfaces and particle size of 200-500 nm, while coprecipitation samples (Figures 2(c) and 2(d)) demonstrate aggregation of particles. More uniform and better dispersed particles were found for CoLS sample. The spherical structure of the catalysts can increase the contact area between soot and catalyst and facilitate oxygen migration in the catalytic reactions, thus improving the catalytic activity for soot combustion. SEMs did not show any significant difference between the morphological features of the as-synthesized LSO-c and CoLS-c samples. The aggregation of the LSO-c and CoLS-c particles may be caused by the high calcination temperature and the high surface energy [34]. Figure 3 showed a narrow particle distribution centered at $100-500 \mathrm{~nm}$. In this case, most of histograms are unimodal except for CoLS sample. According to the histogram of particle size distribution, the mean diameter of particles coincides with the results from SEM images.

3.3. $\mathrm{N}_{2}$ Adsorption-Desorption Characterization. $\mathrm{N}_{2}$ physisorption experiments were carried out to examine the texture characteristics of the samples. All the oxides samples presented adsorption isotherms of type IV in the IUPAC classification, which are representative of mesoporous materials with no or few micropores and strong interaction between adsorbent and adsorbate molecules. The hysteresis loops at a high relative pressure indicate a capillary condensation of adsorbate in the meso- and macropores of the solids. The 


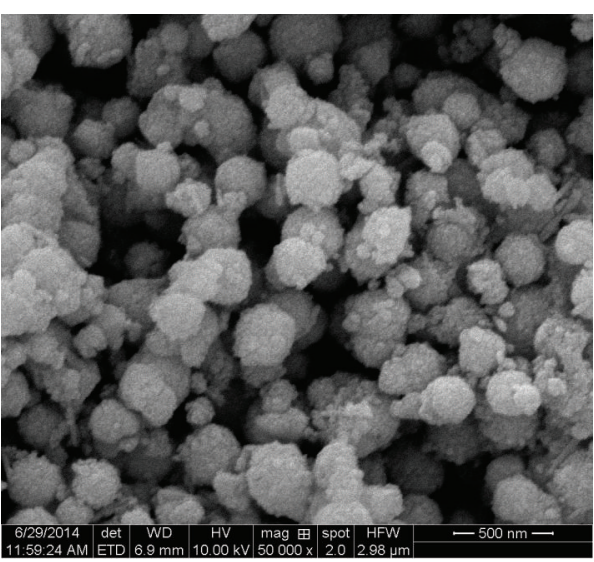

(a)

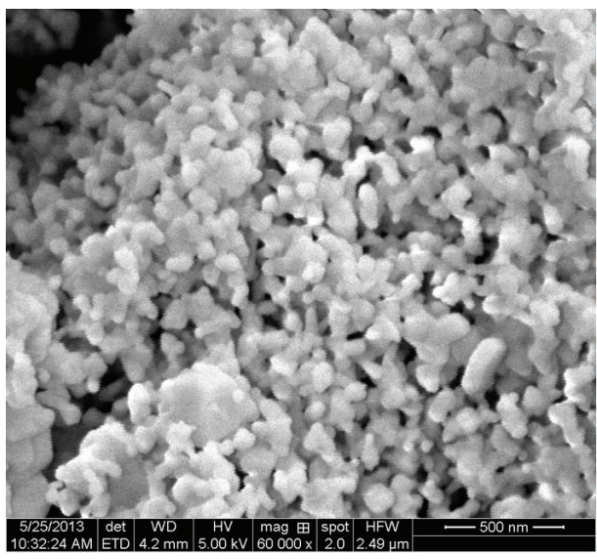

(c)

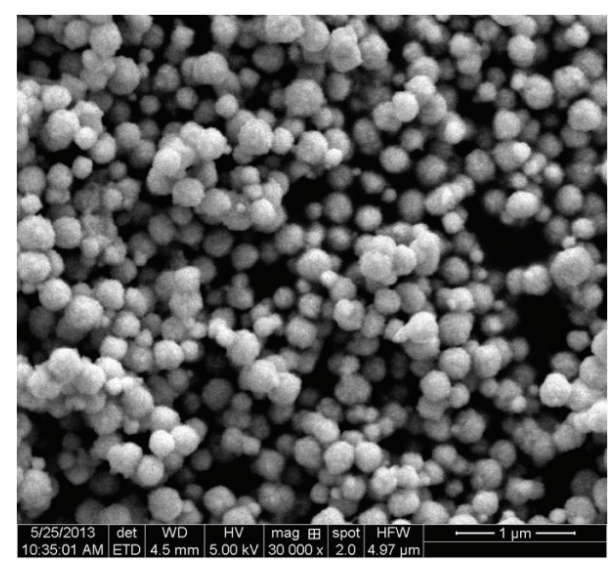

(b)

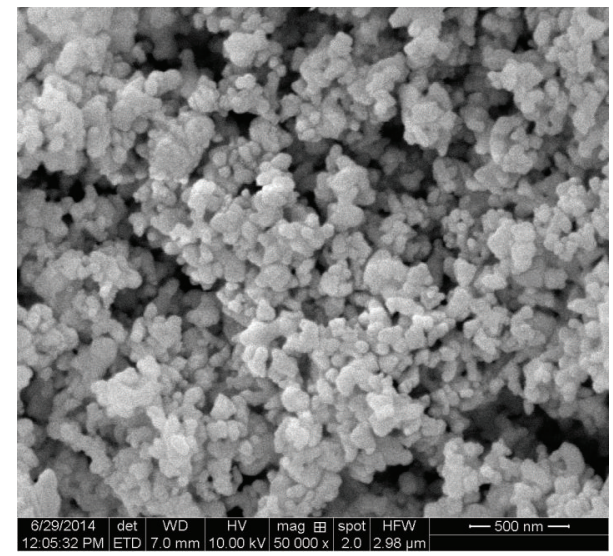

(d)

FIgURE 2: SEM micrographs of LSO (a), CoLS (b), LSO-c (c), and CoLS-c (d) samples.

pyrochlore oxides resemble $\mathrm{H} 3$ type hysteresis loops, which is usually given by adsorbents with slit-shaped pores.

As calculated from the pore size distribution curves (Figure 4 inset), most of the pores fall in mesosize range $\left(2 \mathrm{~nm}<r_{p}<50 \mathrm{~nm}\right)$. The BET specific surface area $\left(S_{\mathrm{BET}}\right)$, total pore volume $\left(V_{P}\right)$, and average pore diameter $\left(D_{P}\right)$ of the mixed oxides determined from isotherms are listed in Table 1. The catalysts via hydrothermal method show larger surface areas and pore volumes, which may be related to their smaller crystallite sizes. The lower surface area of coprecipitation samples may be due to the aggregation of the particles as can be seen from the SEM morphology. The LSO sample exhibits high surface area of $39.0 \mathrm{~m}^{2} / \mathrm{g}$ and large pore volume of $0.057 \mathrm{~cm}^{3} / \mathrm{g}$.

3.4. FTIR Characterization. In pyrochlores the metal ions are situated in two different sublattices designated as tetrahedral (A site) and octahedral (B site) sites according to the geometrical configuration of the neighboring oxygen [35]. It has been reported that pyrochlore oxides exhibit seven IR bands in the range of $750-50 \mathrm{~cm}^{-1}$ originating from vibration and bending of metal-oxygen bonds [23]. The band at about $600 \mathrm{~cm}^{-1}$ is from the $\mathrm{B}-\mathrm{O}$ stretching vibrations in the $\mathrm{BO}_{6}$ octahedron and the band around $400 \mathrm{~cm}^{-1}$ to the A-O stretching vibrations. The IR spectra of the pyrochlore catalysts recorded in the range of $400-1000 \mathrm{~cm}^{-1}$ are shown in Figure 5. At about $600 \mathrm{~cm}^{-1}$, one broad band ascribable to $\mathrm{Sn}-\mathrm{O}$ stretching vibration was observed for each sample. The $v(\mathrm{Sn}-\mathrm{O})$ based on IR spectra of the catalysts is shown in Table 1 . The $v(\mathrm{Sn}-\mathrm{O})$ of hydrothermal samples shifts to high frequency compared to the coprecipitation samples, indicating changes in $\mathrm{Sn}-\mathrm{O}$ bond strength. The differences in $\nu(\mathrm{Sn}-\mathrm{O})$ resulting from different preparation conditions were also reported [36]. These changes in $\mathrm{Sn}-\mathrm{O}$ bond strength may influence oxygen mobility of the catalysts because the Sn$\mathrm{O}$ bond is responsible for the release of lattice oxygen when enough energy is provided [24]. This can also be related to the TPR results where the reducibility of the samples was enhanced after Co doped in the $\mathrm{La}_{2} \mathrm{Sn}_{2} \mathrm{O}_{7}$ pyrochlore.

3.5. Temperature-Programmed Reduction with $\mathrm{H}_{2}$. The $\mathrm{H}_{2}$ TPR profiles of pyrochlores oxides, presented in Figure 6, show that the materials possess considerably different reducibility. LSO sample displays a wide low temperature peak at $564^{\circ} \mathrm{C}$ and a high temperature peak above $700^{\circ} \mathrm{C}$, which belongs to the reduction of $\mathrm{Sn}^{4+}$ to $\mathrm{Sn}^{2+}$ and $\mathrm{Sn}^{2+}$ to 

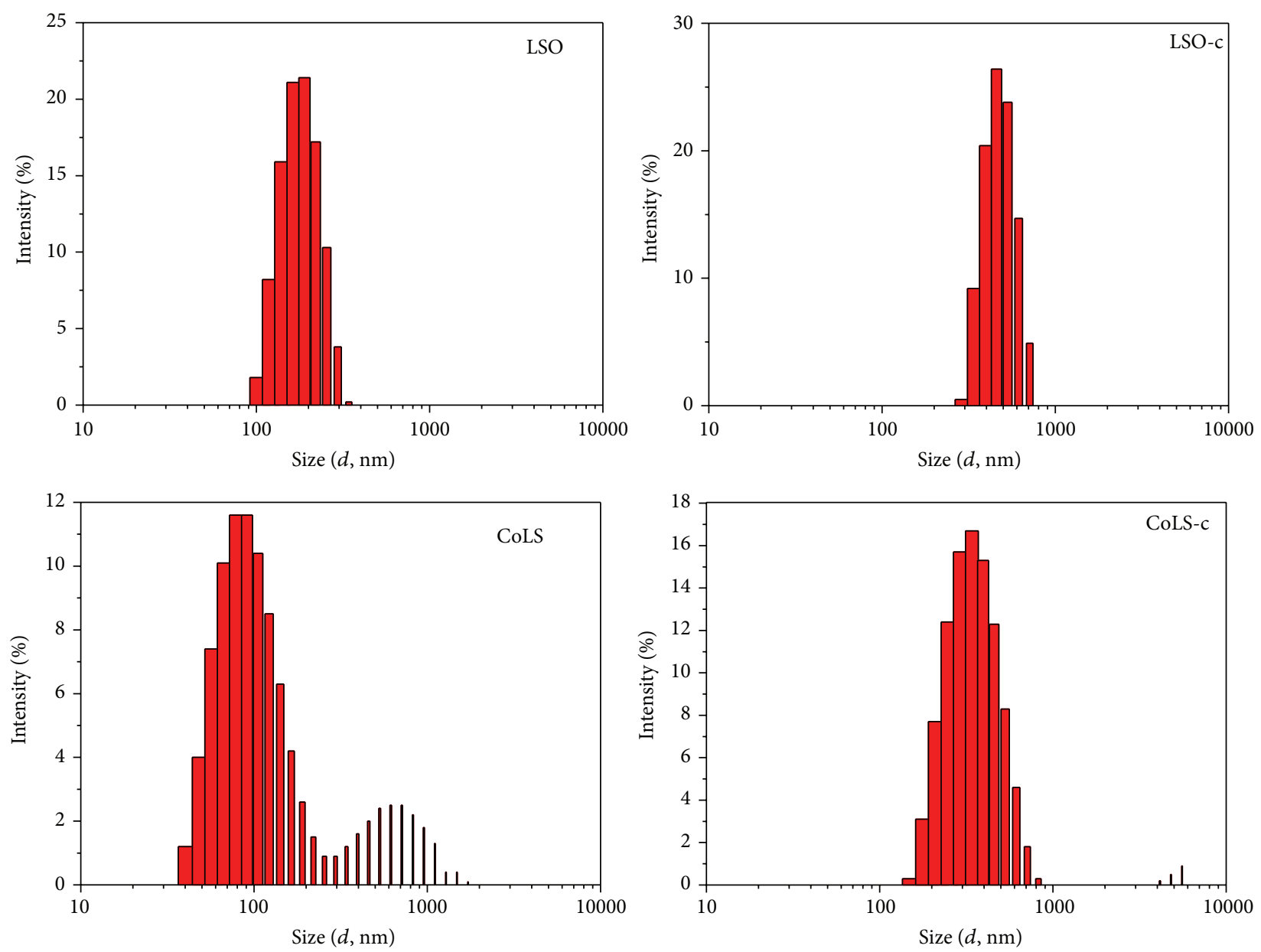

FIGURE 3: Histograms of particle size distribution.

$\mathrm{Sn}^{0}$, respectively. A further reduction behavior is observed on the catalyst of CoLS, which presents a large $\mathrm{H}_{2}$ consumption peak around $225^{\circ} \mathrm{C}$ attributed to the reduction of $\mathrm{Co}^{3+}$ to $\mathrm{Co}^{2+}$. The complete reduction of $\mathrm{Co}^{2+}$ to $\mathrm{Co}^{0}$ only takes place at higher temperature (about $406^{\circ} \mathrm{C}$ ). Similar reduction phenomena were observed on the LSO-c and CoLS-c samples. In comparison with the samples by coprecipitation method, the catalysts via hydrothermal route show enhanced reduction of $\mathrm{Sn}^{4+}$ to $\mathrm{Sn}^{2+}$, which may be linked to the changes in $\mathrm{Sn}-\mathrm{O}$ bond strength. Furthermore, small amounts of $\mathrm{Sn}$ replaced by cobalt metals influence the reduction behavior, especially on the low temperature range, which is due to the interactions between Sn and cobalt metals. It can be seen from the onset temperature for reduction that the reducibility decreases by the following order: CoLS $>$ LSO $>$ CoLS-c $>$ LSO-c.

3.6. Catalytic Performance of Soot Oxidation. The soot conversion profiles obtained during catalytic tests with $\mathrm{O}_{2}$ are plotted as a function of temperature in Figure 7. The derived parameters of $T_{5}, T_{50}, T_{90}$, and $S_{\mathrm{CO}_{2}}$ are listed in Table 2. As shown in Figure 7, the blank experiment with $\mathrm{O}_{2}$ was performed mixing the soot with $\mathrm{SiO}_{2}$, and the ignition temperature $\left(T_{5}\right)$ was $470^{\circ} \mathrm{C}$. In comparison with the
TABLE 2: The catalytic performance of catalysts for soot combustion.

\begin{tabular}{lcccc}
\hline Samples & $T_{5}\left({ }^{\circ} \mathrm{C}\right)$ & $T_{50}\left({ }^{\circ} \mathrm{C}\right)$ & $T_{90}\left({ }^{\circ} \mathrm{C}\right)$ & $S_{\mathrm{CO}_{2}}(\%)$ \\
\hline $\mathrm{SiO}_{2}$ & 470 & 590 & 633 & 37.8 \\
$\mathrm{LSO}$ & 377 & 495 & 535 & 95.4 \\
$\mathrm{LSO}-\mathrm{c}$ & 426 & 534 & 580 & 79.7 \\
CoLS & 342 & 457 & 507 & 96.9 \\
CoLS-c & 383 & 473 & 524 & 97.7 \\
\hline
\end{tabular}

noncatalyzed soot oxidation, soot conversion curves over the pyrochlore catalysts shift to lower temperature range with $T_{5}, T_{50}$, and $T_{90}$ decreased and $S_{\mathrm{CO}_{2}}$ increased. As can be seen from Figure 7 and Table 2, the samples by hydrothermal method are more active than that by coprecipitation method, which can be ascribed to the following reasons: (1) the spherical morphology and better dispersed particles with smaller size can increase the contact points with soot; (2) high surface area and pore volumes will favor of gas molecule diffusion in the pores; (3) the improved oxygen mobility induced from the changes in $\mathrm{Sn}-\mathrm{O}$ bond strength.

Furthermore, the Co-doped pyrochlores exhibit higher activity and selectivity than the undoped catalysts, which may 

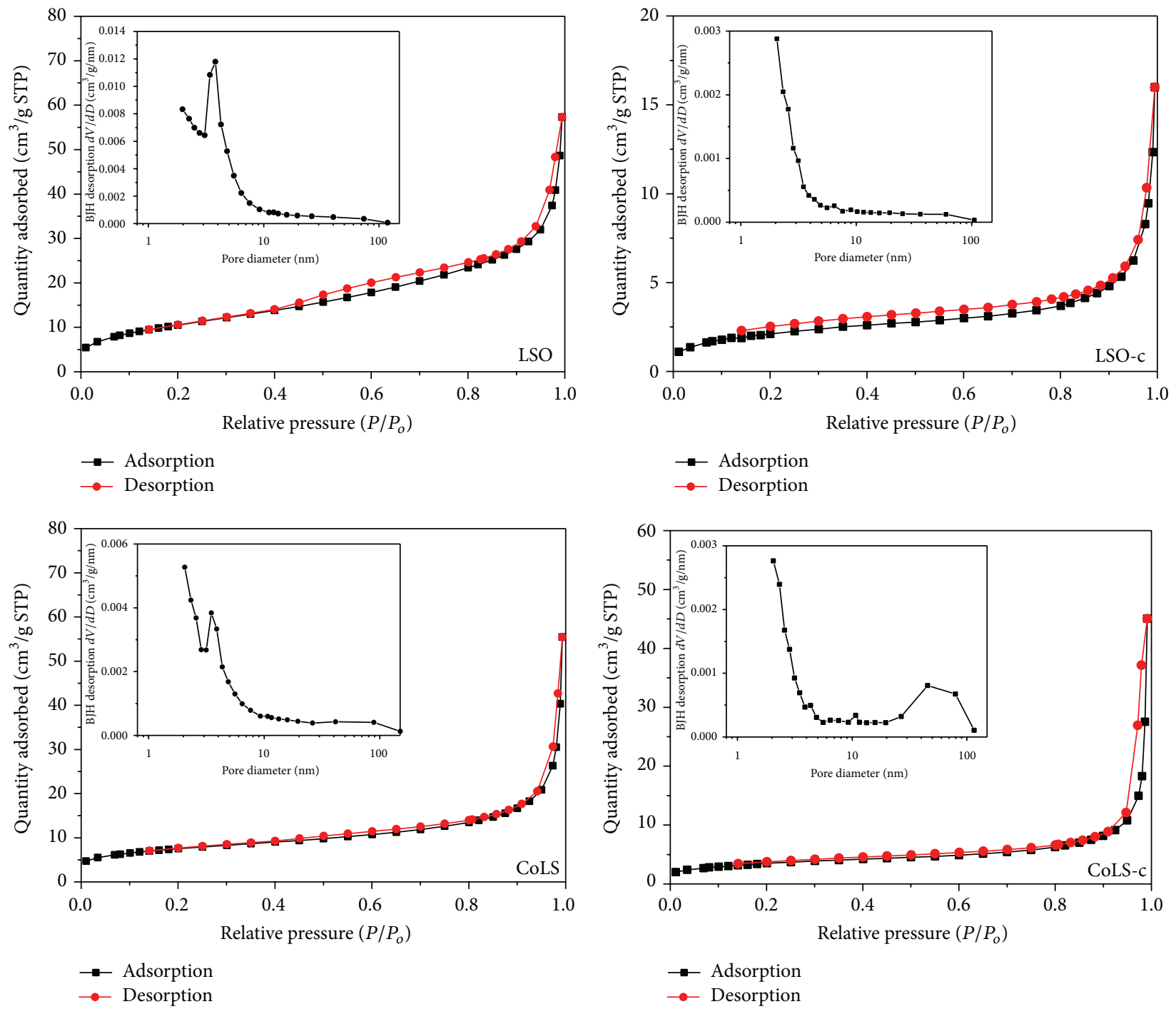

FIGURE 4: $\mathrm{N}_{2}$ adsorption-desorption isotherms and pore size distribution of the samples.

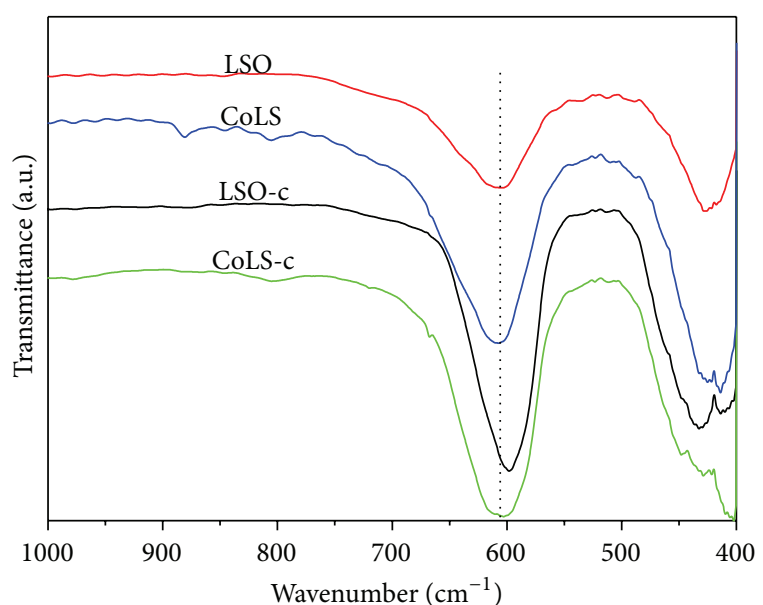

FIGURE 5: Infrared spectra of the Sn-O stretching vibration of samples.

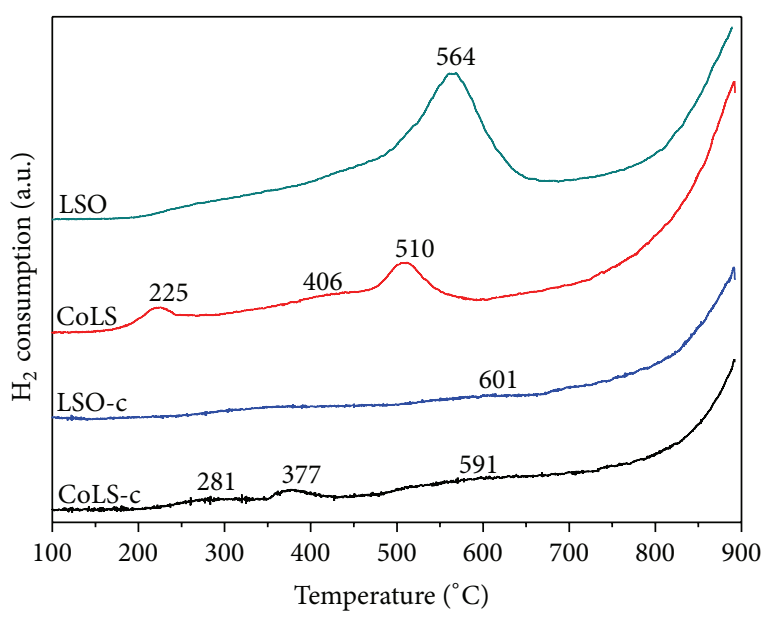

FIGURE 6: $\mathrm{H}_{2}$-TPR profiles of pyrochlore samples. 


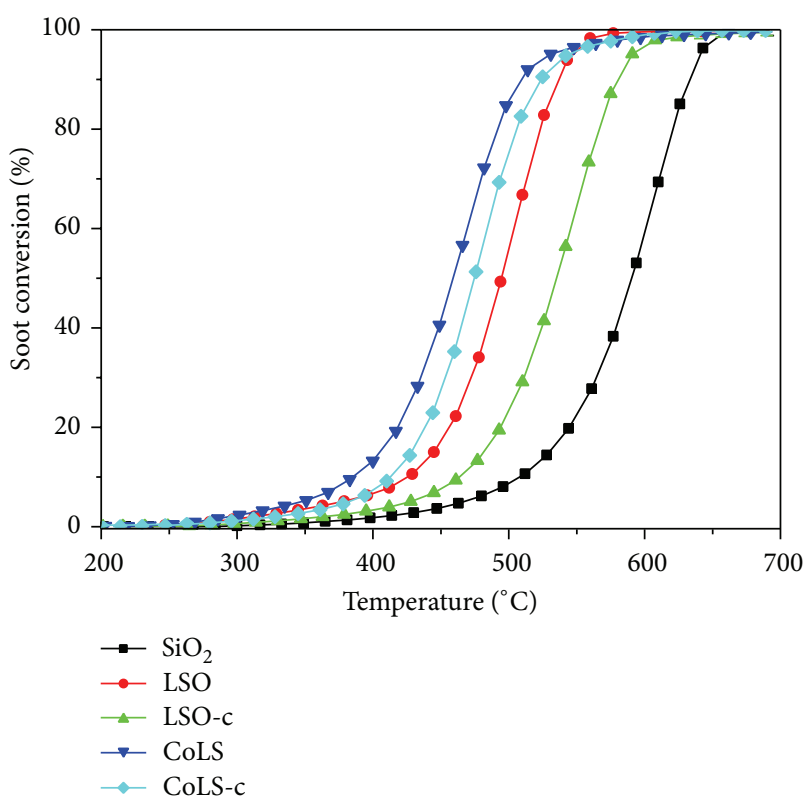

Figure 7: Temperature dependence of soot catalytic combustion over pyrochlore catalysts.

be ascribed to the enhancement of reducibility confirmed by TPR. Among all samples, CoLS possessed the best activity with soot ignition temperature of $342^{\circ} \mathrm{C}$ and high selectivity to $\mathrm{CO}_{2}$ formation of $96.9 \%$. It is well known that the incorporation of functional dopant to A or B sites in the pyrochlore lattice leads to defect structures and thus creates more active sites to make catalytic activity improved [23]. Reactivity of metal oxides is largely dependent on the degree of the coordinative unsaturation of the metal ions. The incorporation of cobalt ions in the pyrochlore structure leads to the formation of oxygen vacancies and makes local structure changed where the coordinative unsaturation of specific $\mathrm{Sn}$ ions increases. In general, the high activity of the CoLS catalyst is attributed to the enhancement of reducibility and the surface oxygen vacancy formed during the breakage of metal-oxygen lattice bond besides the three points mentioned above.

\section{Conclusions}

Nanocrystalline $\mathrm{La}_{2} \mathrm{Sn}_{2} \mathrm{O}_{7}$ and $\mathrm{La}_{2} \mathrm{Sn}_{1.8} \mathrm{Co}_{0.2} \mathrm{O}_{7}$ pyrochlore catalysts were synthesized by hydrothermal method at temperatures as low as $180^{\circ} \mathrm{C}$. Relatively uniform spherical structure with particle size of $200-500 \mathrm{~nm}$ was produced via hydrothermal route. These catalysts also presented larger specific surface area and pore volume, which were benefit to the adsorption and desorption of gas molecules in the catalytic reaction. Both oxygen mobility and reducibility of the catalysts were improved which may be linked to the changes in $\mathrm{Sn}-\mathrm{O}$ bond strength. The samples via hydrothermal route are more active for catalytic soot combustion than that by coprecipitation method, which may be related to the spherical morphology, high surface area, and improved oxygen mobility. Besides the three points mentioned above, the Co-doped pyrochlores exhibit higher activities which may be ascribed to the enhancement of reducibility and the formed surface oxygen vacancy. Among all samples, $\mathrm{La}_{2} \mathrm{Sn}_{1.8} \mathrm{Co}_{0.2} \mathrm{O}_{7}$ possessed the best activity with soot ignition temperature of $342^{\circ} \mathrm{C}$ and high selectivity to $\mathrm{CO}_{2}$ formation of $96.9 \%$ under $\mathrm{O}_{2}$ atmosphere.

\section{Conflict of Interests}

The authors declare that there is no conflict of interests regarding the publication of this paper.

\section{Acknowledgments}

This work was financially supported by the National Natural Science Foundation of China (nos. 21007019 and 21277059), the Development Program of the Science and Technology of Shandong Province (no. 2014GSF117039), Jinan Science and Technology Development Plan (no. 201303066), and National Science \& Technology Pillar Program (2014BAK13B02).

\section{References}

[1] S. Menon, J. Hansen, L. Nazarenko, and Y. Luo, "Climate effects of black carbon aerosols in China and India," Science, vol. 297, no. 5590, pp. 2250-2253, 2002.

[2] J. P. A. Neeft, M. Makkee, and J. A. Moulijn, "Catalysts for the oxidation of soot from diesel exhaust gases. I. An exploratory study," Applied Catalysis B: Environmental, vol. 8, no. 1, pp. 5778, 1996.

[3] Y. C. Wei, J. Liu, Z. Zhao et al., "Highly active catalysts of gold nanoparticles supported on three-dimensionally ordered macroporous $\mathrm{LaFeO}_{3}$ for soot oxidation," Angewandte Chemie International Edition, vol. 50, no. 10, pp. 2326-2329, 2011.

[4] Y. Teraoka and S. Kagawa, "Simultaneous catalytic removal of NOx and diesel soot particulates," Catalysis Surveys from Japan, vol. 2, no. 2, pp. 155-164, 1998.

[5] F. E. López-Suárez, A. Bueno-López, M. J. Illán-Gómez, A. Adamski, B. Ura, and J. Trawczynski, "Copper catalysts for soot oxidation: alumina versus perovskite supports," Environmental Science \& Technology, vol. 42, no. 20, pp. 7670-7675, 2008.

[6] D. Reichert, H. Bockhorn, and S. Kureti, "Study of the reaction of $\mathrm{NO}_{x}$ and soot on $\mathrm{Fe}_{2} \mathrm{O}_{3}$ catalyst in excess of $\mathrm{O}_{2}$," Applied Catalysis B: Environmental, vol. 80, no. 3-4, pp. 248-259, 2008.

[7] Z. P. Wang, X. M. Zhang, L. G. Wang et al., "Co-Mn-Al nonstoichiometric spinel-type catalysts derived from hydrotalcites for the simultaneous removal of soot and nitrogen oxides," Science of Advanced Materials, vol. 5, no. 10, pp. 1449-1457, 2013.

[8] R. Kimura, J. Wakabayashi, S. P. Elangovan, M. Ogura, and T. Okubo, "Nepheline from $\mathrm{K}_{2} \mathrm{CO}_{3}$ /nanosized sodalite as a prospective candidate for diesel soot combustion," Journal of the American Chemical Society, vol. 130, no. 39, pp. 12844-12845, 2008.

[9] N. A. Comelli, M. L. Ruiz, N. A. Merino et al., "Preparation and characterisation of calcined $\mathrm{Mg} / \mathrm{Al}$ hydrotalcites impregnated with alkaline nitrate and their activities in the combustion of particulate matter," Applied Clay Science, vol. 80-81, pp. 426432, 2013. 
[10] Z. Zhang, Y. Zhang, Z. Wang, and X. Gao, "Catalytic performance and mechanism of potassium-promoted Mg-Al hydrotalcite mixed oxides for soot combustion with $\mathrm{O}_{2}$," Journal of Catalysis, vol. 271, no. 1, pp. 12-21, 2010.

[11] M. E. Gálvez, S. Ascaso, I. Tobías, R. Moliner, and M. J. Lázaro, "Catalytic filters for the simultaneous removal of soot and NOx: influence of the alumina precursor on monolith washcoating and catalytic activity," Catalysis Today, vol. 191, no. 1, pp. 96-105, 2012.

[12] Y. Teraoka, K. Nakano, S. Kagawa, and W. F. Shangguan, "Simultaneous removal of nitrogen oxides and diesel soot particulates catalyzed by perovskite-type oxides," Applied Catalysis B: Environmental, vol. 5, no. 3, pp. L181-L185, 1995.

[13] X. Wang, Y. Zhang, Q. Li, Z. Wang, and Z. Zhang, "Identification of active oxygen species for soot combustion on $\mathrm{LaMnO}_{3}$ perovskite," Catalysis Science \& Technology, vol. 2, no. 9, pp. 1822-1824, 2012.

[14] J. Oi-Uchisawa, S. D. Wang, T. Nanba, A. Ohi, and A. Obuchi, "Improvement of Pt catalyst for soot oxidation using mixed oxide as a support," Applied Catalysis B: Environmental, vol. 44, no. 3, pp. 207-215, 2003.

[15] E. Aneggi, D. Wiater, C. de Leitenburg, J. Llorca, and A. Trovarelli, "Shape-dependent activity of ceria in soot combustion," ACS Catalysis, vol. 4, no. 1, pp. 172-181, 2014.

[16] Z. P. Wang, L. G. Wang, F. He, Z. Jiang, T. C. Xiao, and Z. L. Zhang, "Catalytic soot oxidation over $\mathrm{Ce}$ - and $\mathrm{Cu}$-doped hydrotalcites-derived mesoporous mixed oxides," Journal of Nanoscience and Nanotechnology, vol. 14, no. 9, pp. 7087-7096, 2014.

[17] J. Lian, L. M. Wang, S. X. Wang, J. Chen, L. A. Boatner, and R. C. Ewing, "Nanoscale manipulation of pyrochlore: new nanocomposite ionic conductors," Physical Review Letters, vol. 87, no. 14, Article ID 145901, 2001.

[18] R. A. McCauley and F. A. Hummel, "New pyrochlores of the charge-coupled type," Journal of Solid State Chemistry, vol. 33, no. 1, pp. 99-105, 1980.

[19] M. H. Zahir, T. Suzuki, Y. Fujishiro, and M. Awano, "Hydrothermal synthesis of Sr-Ce-Sn-Mn-O mixed oxidic/stannate pyrochlore and its catalytic performance for NO reduction," Materials Chemistry and Physics, vol. 116, no. 1, pp. 273-278, 2009.

[20] Y. Teraoka, K.-I. Torigoshi, H. Yamaguchi, T. Ikeda, and S. Kagawa, "Direct decomposition of nitric oxide over stannate pyrochlore oxides: relationship between solid-state chemistry and catalytic activity," Journal of Molecular Catalysis A: Chemical, vol. 155, no. 1-2, pp. 73-80, 2000.

[21] Y. Xuan, C. H. He, R. Wang, R. Liu, and Y. Q. Jia, "A novel CO conversion catalyst," Catalysis Letters, vol. 46, no. 1-2, pp. 119121, 1997.

[22] Z. Jiang, J. Su, Y. Han, F. Alshahrani, Z. Hao, and T. Xiao, "The effects of transition metal in Sn-based pyrochlores on the methane catalytic combustion," Progress in Natural Science, vol. 15, pp. 134-138, 2005.

[23] J. Cheng, H. L. Wang, Z. P. Hao, and S. B. Wang, "Catalytic combustion of methane over cobalt doped lanthanum stannate pyrochlore oxide," Catalysis Communications, vol. 9, no. 5, pp. 690-695, 2008.

[24] Z. P. Wang, F. He, Q. Li, and L. G. Wang, "Catalytic oxidation of diesel soot over transition metal doped lanthanum stannate pyrochlores with a O2/NO mixture," Procedia Engineering, vol. 24, pp. 436-440, 2011.
[25] Y. Xin, X. Yang, P. Jiang, Z. Zhang, Z. Wang, and Y. Zhang, "Synthesis of $\mathrm{CeO}_{2}$-based quantum dots through a polyolhydrolysis method for fuel-borne catalysts," ChemCatChem, vol. 3, no. 11, pp. 1772-1778, 2011.

[26] X. Peng, L. Manna, W. Yang et al., "Shape control of CdSe nanocrystals," Nature, vol. 404, no. 6773, pp. 59-61, 2000.

[27] J. Liu, Z. Zhao, C. M. Xu, A. J. Duan, and G. Y. Jiang, " $\mathrm{CeO}_{2}$ supported vanadium oxide catalysts for soot oxidation: the roles of molecular structure and nanometer effect," Journal of Rare Earths, vol. 28, no. 2, pp. 198-204, 2010.

[28] J. Lian, K. B. Helean, B. J. Kennedy, L. M. Wang, A. Navrotsky, and R. C. Ewing, "Effect of structure and thermodynamic stability on the response of lanthanide stannate pyrochlores to ion beam irradiation," Journal of Physical Chemistry B, vol. 110, no. 5, pp. 2343-2350, 2006.

[29] S. M. Wang, Z. L. Xiu, M. K. Lü, A. Y. Zhang, Y. Y. Zhou, and Z. S. Yang, "Combustion synthesis and luminescent properties of $\mathrm{Dy}^{3+}$-doped $\mathrm{La}_{2} \mathrm{Sn}_{2} \mathrm{O}_{7}$ nanocrystals," Materials Science and Engineering B: Solid-State Materials for Advanced Technology, vol. 143, no. 1-3, pp. 90-93, 2007.

[30] H. Zhu, D. Jin, L. Zhu, H. Yang, K. Yao, and Z. Xi, "A general hydrothermal route to synthesis of nanocrystalline lanthanide stannates: $\mathrm{Ln}_{2} \mathrm{Sn}_{2} \mathrm{O}_{7}(\mathrm{Ln}=\mathrm{Y}, \mathrm{La}-\mathrm{Yb})$," Journal of Alloys and Compounds, vol. 464, no. 1-2, pp. 508-513, 2008.

[31] Z. Zhang, Y. X. Zhang, Q. Y. Su, Z. P. Wang, Q. Li, and X. Y. Gao, "Determination of intermediates and mechanism for soot combustion with $\mathrm{NO}_{x} / \mathrm{O}_{2}$ on potassium-supported $\mathrm{Mg}$ Al hydrotalcite mixed oxides by in situ FTIR," Environmental Science and Technology, vol. 44, no. 21, pp. 8254-8258, 2010.

[32] Z. Wang, X. Yan, X. Bi et al., "Lanthanum-promoted copperbased hydrotalcites derived mixed oxides for NOx adsorption, soot combustion and simultaneous NOx-soot removal," Materials Research Bulletin, vol. 51, pp. 119-127, 2014.

[33] K. Li, H. Wang, and H. Yan, "Hydrothermal preparation and photocatalytic properties of $\mathrm{Y}_{2} \mathrm{Sn}_{2} \mathrm{O}_{7}$ nanocrystals," Journal of Molecular Catalysis A: Chemical, vol. 249, no. 1-2, pp. 65-70, 2006.

[34] S. M. Wang, G. J. Zhou, M. K. Lu, Y. Y. Zhou, S. F. Wang, and Z. S. Yang, "Synthesis and characterization of lanthanum stannate nanoparticles," Journal of the American Ceramic Society, vol. 89, no. 9, pp. 2956-2959, 2006.

[35] J. Cheng, J. Li, C. Ma, and Z. Hao, "Catalytic combustion of methane over $\mathrm{La}_{2} \mathrm{TM}_{0.3} \mathrm{Zr}_{1.7} \mathrm{O}_{7-\delta}(\mathrm{TM}=\mathrm{Mn}, \mathrm{Fe}$, and $\mathrm{Co})$ pyrochlore oxides," Catalysis Communications, vol. 10, no. 8, pp. 1170-1173, 2009.

[36] K. Li, T. Zhang, H. Wang, and H. Yan, "Low-temperature synthesis and structure characterization of the serials $\mathrm{Y}_{2-\delta} \mathrm{Bi}_{\delta} \mathrm{Sn}_{2} \mathrm{O}_{7}(\delta=0-2.0)$ nanocrystals," Journal of Solid State Chemistry, vol. 179, no. 4, pp. 1029-1034, 2006. 

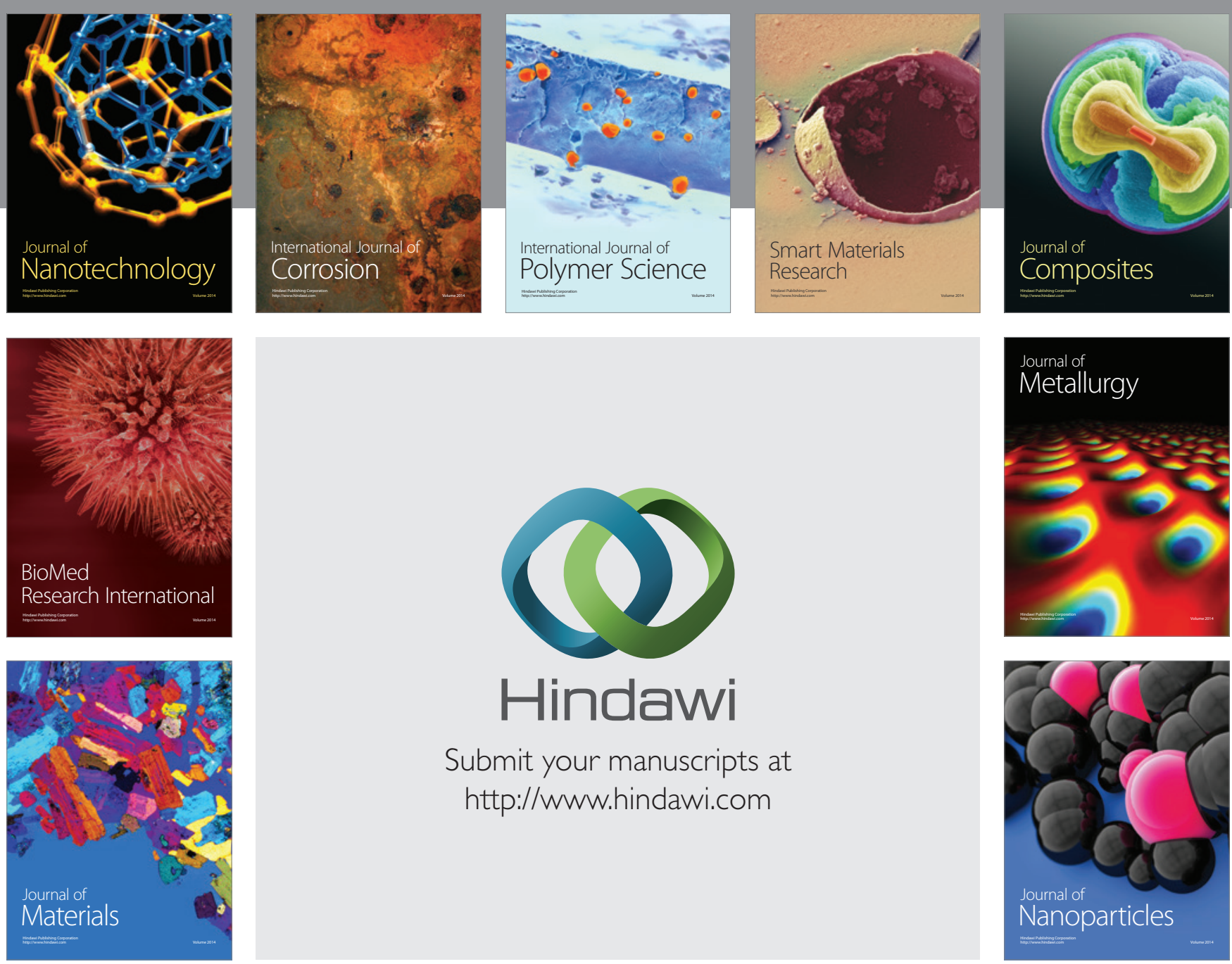

Submit your manuscripts at http://www.hindawi.com
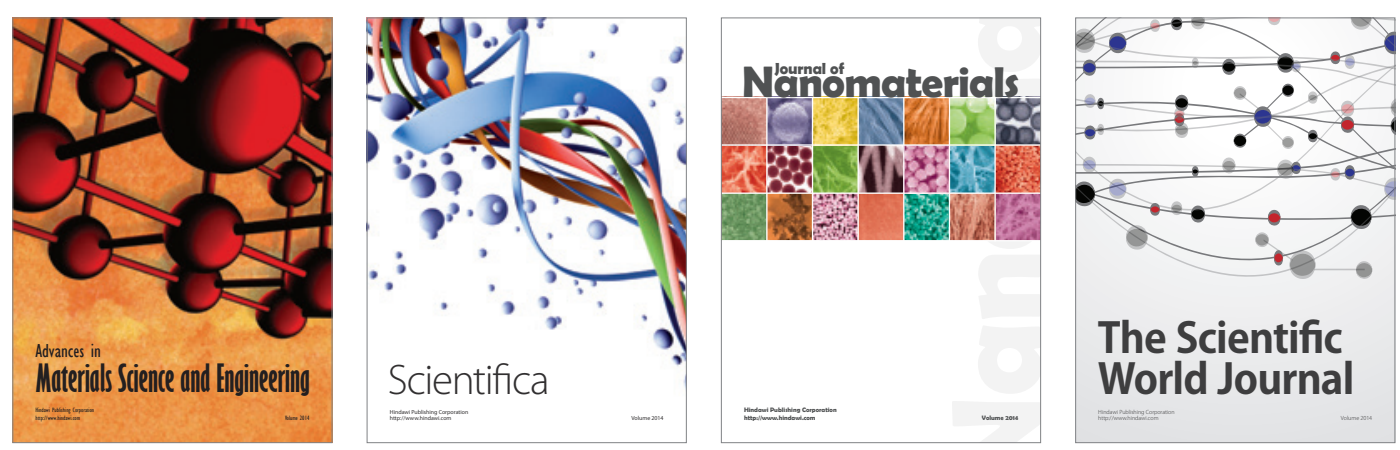

\section{The Scientific World Journal}
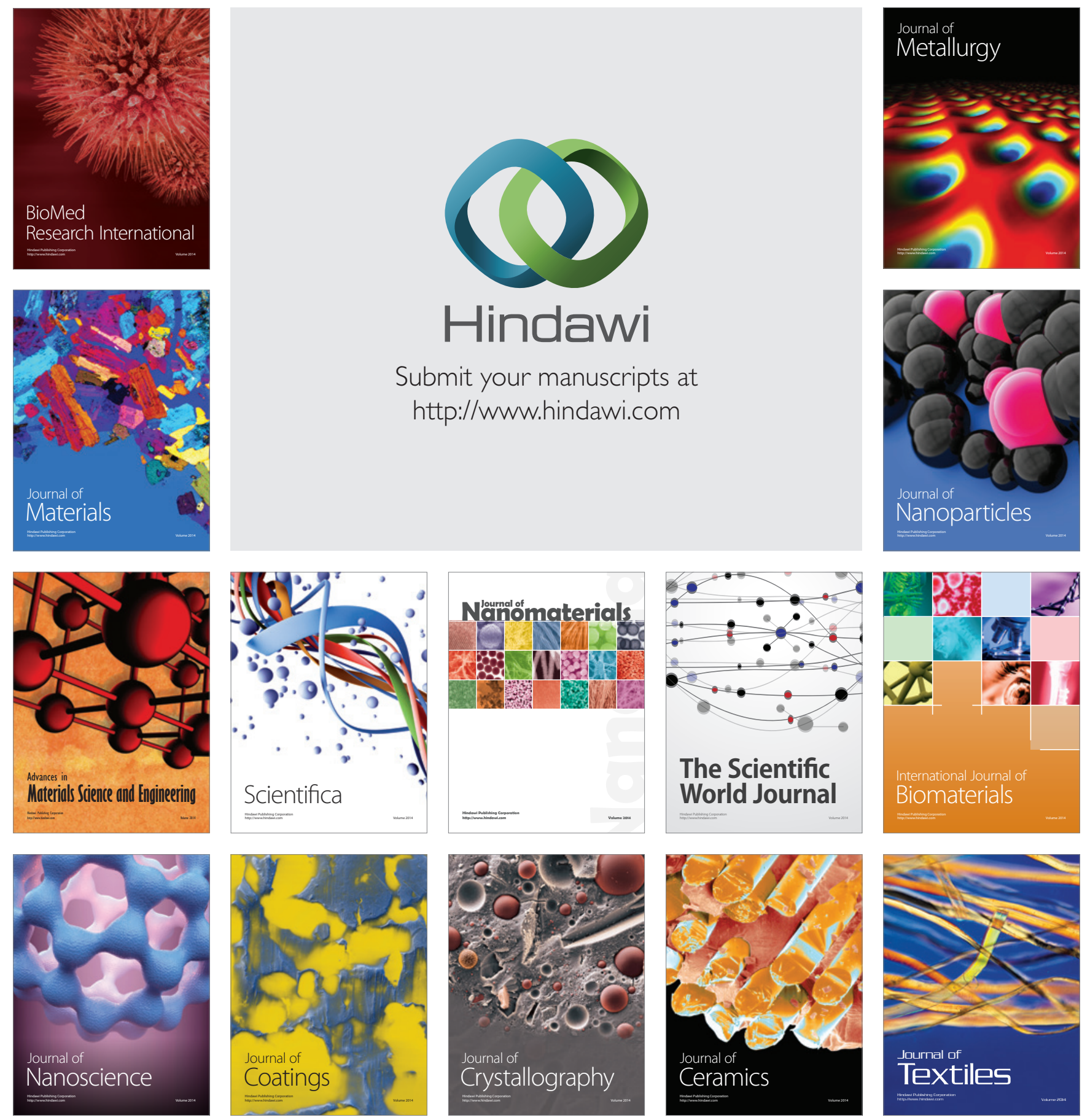